\title{
Effect of high-pressure-jet processing on the viscosity and foaming properties of pasteurized whole milk
}

\author{
M. Tran, ${ }^{*}$ R. Roberts, ${ }^{*}$ T. L. Felix, $\dagger$ and F. M. Harte ${ }^{* 1}$ \\ *Department of Food Science, and \\ †Department of Animal Science, Pennsylvania State University, University Park 16802
}

\begin{abstract}
The processing of milk using high-pressure technologies has been shown to dissociate casein micelles, denature whey proteins, and change the appearance and rheological properties of milk. A novel high-pressure processing technology called high-pressure-jet (HPJ) processing is currently being investigated for use in the food industry. Few studies have evaluated the effects of HPJ technology on dairy foods. The present study investigated the physicochemical and foaming properties of homogenized pasteurized whole milk processed at pressures from 0 to $500 \mathrm{MPa}$ using HPJ processing. The apparent particle size exhibited a monomodal distribution in whole milk samples processed up to 125 $\mathrm{MPa}$ and a bimodal distribution for samples processed at 250, 375, and $500 \mathrm{MPa}$. The viscosity increased from approximately 2 to $5 \mathrm{mPa} \cdot \mathrm{s}$ when whole milk was processed using HPJ at $375 \mathrm{MPa}$, and foam expansion increased from approximately 80 to $140 \%$ after processing at $>125 \mathrm{MPa}$. Foam stability was limited to pressures in the 375 to $500 \mathrm{MPa}$ range. We hypothesized that the increase in apparent particle size was due to the dissociation of casein micelles into surface-active casein protein monomers, and the formation of caseincasein and casein-fat particles. Ultracentrifugation of samples into 3 milk fractions (supernatant, serum, and precipitate), and subsequent fat and protein analysis on the 3 fractions, showed that a strong interaction between casein proteins and fat triglycerides occurred, evidenced by the increase in fat content associated with the precipitate fraction with increasing pressure. This suggests that stable casein-fat aggregates are formed when whole milk is processed using HPJ at pressure $>125 \mathrm{MPa}$.
\end{abstract}

Key words: high-pressure jet, whole milk, foaming, creaming

\footnotetext{
Received November 6, 2017.

Accepted January 8, 2018.

${ }^{1}$ Corresponding author: fmh14@psu.edu
}

\section{INTRODUCTION}

Most research conducted on high pressure involves high-pressure processing, microfluidization, or highpressure homogenization (Tobin et al., 2015; Voigt et al., 2015). High-pressure processing (HPP) has been commercialized in the food industry by utilizing high hydrostatic pressure for nonthermal pasteurization (i.e., to inactivate foodborne pathogens; Feijoo et al., 1997; Mussa and Ramaswamy, 1997; Hayes et al., 2005) and to prevent quality loss (i.e., polyphenol oxidase inactivation in avocado; Palou et al., 1999). The capabilities of HPP are limited because it is a batch process, and industries that process fluid and semi-solid foods prefer continuous processing for increased efficiency. Microfluidization utilizes pressure to push fluids into 2 opposing channels where the liquids impinge, followed by a decrease in pressure, which causes turbulence, resulting in droplet disruption (Tobin et al., 2015). Advantages of using microfluidization include low maintenance, because there are no moving parts in the interaction chamber, and the ability to produce fine emulsions with narrower particle size distribution. Limitations include pressure ranges from 20 to $275 \mathrm{MPa}$ and possible increase of fat globule size and coalescence due to "over-processing" at higher pressures, which also occur during HPP (Jafari et al., 2007). High-pressure homogenization (HPH) is a continuous process that utilizes a pump to push fluids through a ball-seat or needle-seat shear-resistant valve at pressures up to $400 \mathrm{MPa}$. The act of forcing fluids through the resistant valve creates a combination of physical phenomena including high hydrostatic pressure, shear, turbulence, cavitation, impingement, and temperature (Paquin, 1999). These physical phenomena cause physicochemical changes to foods processed using HPH.

Advances in material science and engineering have enabled high-pressure jet (HPJ) technology to achieve processing pressures up to $600 \mathrm{MPa}$. The HPJ is equipped with a diamond, sapphire, or ruby nozzle (75 to $400 \mu \mathrm{m}$ in diameter) to restrict the flow into a jet stream. Similarly to HPH, physical phenomena in- 
cluding high hydrostatic pressure, turbulence, cavitation, and temperature occur in the HPJ nozzle. Studies conducted on raw and pasteurized skim and whole milk systems using HPH showed significant changes in fat globule and casein micelle size depending on pressures applied. Studies have reported a reduction in apparent particle size of fat globules at pressures between 200 and $250 \mathrm{MPa}$ (Hayes and Kelly, 2003; Thiebaud et al., 2003; Hayes et al., 2005). At pressures $\geq 250 \mathrm{MPa}$, an increase in fat globule size has been observed, possibly due to clustering and coalescence of newly formed fat globules (Thiebaud et al., 2003; Pereda et al., 2007). Casein micelles processed under $\mathrm{HPH}$ are disrupted and decrease in size at pressures of 100 to $200 \mathrm{MPa}$, whereas micelle size appears to increase at pressure between 200 and $350 \mathrm{MPa}$ (Hayes and Kelly, 2003; Sandra and Dalgleish, 2005; Roach and Harte, 2008; Lodaite et al., 2009). High-pressure homogenization at $>350 \mathrm{MPa}$ without cooling induces whey protein denaturation due to a shear-induced increase in temperature. The increase in temperature creates complexes between denatured $\beta-\mathrm{LG}$ and casein micelles, causing an increase in apparent casein micelle size (Hayes et al., 2005; Zobrist et al., 2005; Pereda et al., 2007). The extent of whey protein denaturation depends on the efficiency of the heat exchanger to cool the sample.

Pasteurized skim milk processed with HPJ from 0 to $500 \mathrm{MPa}$ (in 100-MPa increments) exhibited significant changes in apparent particle size and increases in apparent viscosity and rennet coagulation time, as well as improved foaming and emulsifying properties (Harte et al., 2016; Mohan et al., 2016). The increased foamability and emulsifying properties were due to partial disruption of casein micelles, causing an increase of protein adsorption to the interface and partially heatinduced whey protein denaturation (Harte et al., 2016).

High-pressure-jet processing of pasteurized skim milk has led to modified functionality of casein micelles, creating the potential to use HPJ processing for novel dairy food applications. However, dairy foods are complex systems in which interactions of multiple components such as milk fat and proteins contribute to the structure and integrity. Therefore, investigating simpler systems such as pasteurized whole milk will aid in further understanding of HPJ processing capabilities for the food industry.

We hypothesized that dissociation of casein micelles by HPJ processing of whole milk will lead to improved foamability by creating stable casein-fat aggregates. Therefore, the objective of this study was to investigate the effect of HPJ processing on the physicochemical and foaming properties of pasteurized whole milk.

\section{MATERIALS AND METHODS}

\section{HPJ Processing of Pasteurized Whole Milk}

Pasteurized and homogenized whole milk was purchased from the Penn State Berkey Creamery (University Park, PA). The milk was kept at $4^{\circ} \mathrm{C}$ before HPJ processing from 125 to $500 \mathrm{MPa}$ in $125-\mathrm{MPa}$ increments using a Hyperjet 94i-S pump system (Flow Internationals Corp., Kent, WA). The control sample (0 MPa gauge pressure) was not subject to HPJ processing. The milk was forced through a 10- $\mu \mathrm{m}$-diameter diamond nozzle.

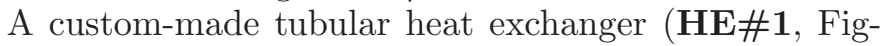
ure 1; outer tube diameter of $7.6 \mathrm{~cm}$ and inner tube diameter $5.1 \mathrm{~cm}$, with a height of $122 \mathrm{~cm}$ ) connected to a temperature-controlled water bath was placed before the nozzle and was used to maintain temperature of the milk at $55^{\circ} \mathrm{C}$ or $5^{\circ} \mathrm{C}$. A second heat exchanger (HE\#2, Figure 1; outer tube diameter of $7.6 \mathrm{~cm}$ and inner tube diameter $5.7 \mathrm{~cm}$, with a height of $152.4 \mathrm{~cm}$ ) was placed after the nozzle to contain and cool the HPJ-processed milk. Cooled water $\left(2-4^{\circ} \mathrm{C}\right)$ provided by the Department of Food Science pilot plant was pumped through HE\#2 to rapidly cool the HPJ-processed milk. A hose was connected to the bottom of HE\#2 to collect the milk. Three thermocouples were placed on the system: before the first heat exchanger (TC\#1), before the nozzle (TC\#2) to indirectly monitor temperature of the milk, and to directly measure exit temperature of the samples (TC\#3; Figure 1). The flow rate was determined by measuring the time required to collect a known volume of milk. After the samples were processed, the pump was cleaned with domestic water, a neutral detergent (Soft Clean No. 379, Hydrite, Brookfield, WI), and food-grade sanitizer (XY, EcoLab, St. Paul, MN), and rinsed with domestic water. The HPJ-processed milks were stored at $4^{\circ} \mathrm{C}$ and analyzed within $5 \mathrm{~d}$.

\section{Apparent Particle Size and Fat Globule Size}

Apparent particle size distribution of HPJ-processed milks was determined by static light scattering using a Horiba LA-920 particle size analyzer (Horiba Scientific, Edison, NJ). The milk fat refractive index was 1.14 , which was calculated as the refractive index of the particle (1.52 for milk fat) divided by the refractive index of the diluent (1.33 for water). The HPJ-processed milks were transferred into the particle size analyzer until transmittance equilibrated between 70 and $90 \%$ and further analyzed for volume-surface mean diameter $\left(d_{4,3}\right)$.

Apparent fat globule size was measured using the method of Huppertz et al. (2011). Briefly, samples were 
mixed 1:1 with $0.4 M$ trisodium citrate, containing $4 \%$ (wt/vol) SDS. The mixture of trisodium citrate and SDS dissociates casein micelles (Walstra, 1990) and removes absorbed materials from the oil-water interface (De Feijter et al., 1987) to isolate fat globules. The mean of 3 replicates were used to calculate the volumemean diameter of apparent particle size and apparent fat globule size, $d_{4,3}$.

\section{Density and Rheological Properties}

Density was measured by taking the tare weight of a graduated cylinder on an analytical balance and filling the cylinder with HPJ-processed whole milk to the $500 \mathrm{~mL}$ graduated line. Any foam produced after HPJ processing was not included in density measurements. The density $(\mathrm{g} / \mathrm{mL})$ of all samples was calculated by determining the weight of $500 \mathrm{~mL}$ of milk contained in a volumetric flask.

Newtonian viscosity of HPJ-processed milk was obtained by flow curves (shear strain rate from 1 to 100 1/s; $20^{\circ} \mathrm{C}$ ) using the Discovery H3 Hybrid Rheometer (TA Instruments, New Castle, DE) equipped with a concentric cylinder geometry (inside diameter $40.77 \mathrm{~mm}$, outside diameter $43.88 \mathrm{~mm}$, cup diameter $30.32 \mathrm{~mm}$ ). Viscosity values were obtained using as the slope of the shear stress versus shear rate line using the Trios software (ver. 4.1.1.33073, TA Instruments). Two density and viscosity measurements were done and averaged for each replicate sample.

\section{Foaming Properties}

The preparation of HPJ-processed milk foams was completed using a method adapted from Giardina et al., (2004). In brief, $10 \mathrm{~mL}$ of the control (0 MPa) or HPJ-processed milk samples $(125-500 \mathrm{MPa})$ was placed in a $50-\mathrm{mL}$ graduated centrifuge tube (VWR, Radnor, PA) and vigorously agitated using a vortex on maximum speed for 1 min (Analog vortex mixer 945404, Thermo Fisher Scientific Inc., Waltham, MA). Samples were held at $4^{\circ} \mathrm{C}$ before foaming. Total foam volume and any drained liquid were measured immediately after agitation. Foam expansion was measured by the foam expansion index (FE\%) using Equation [1]:

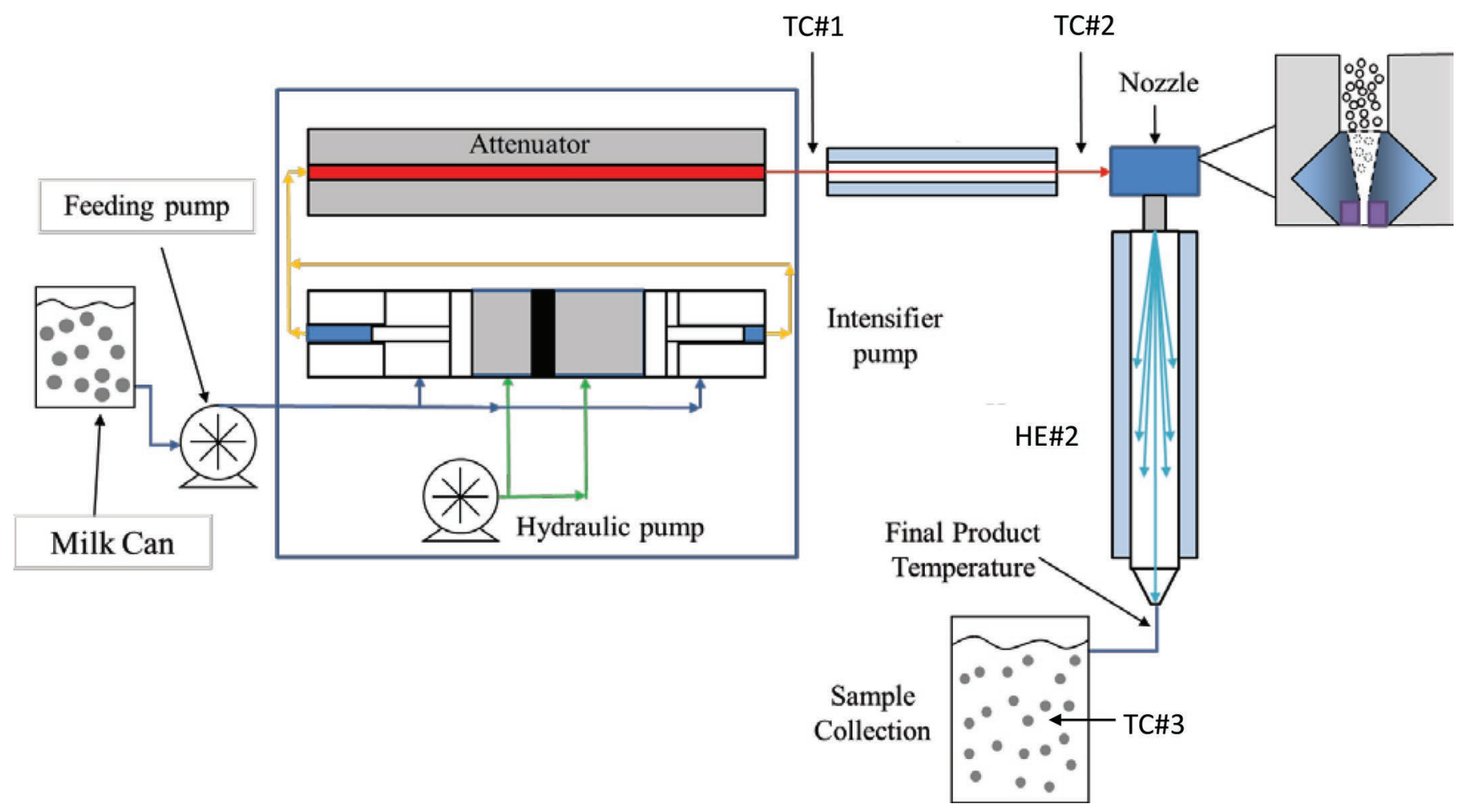

Figure 1. Schematic of modified waterjet system for high-pressure jet (HPJ) processing, where TC $=$ thermocouple, HE $=$ heat exchanger; TC\#1 and TC\#2 measured temperature indirectly outside of the HPJ system, and TC\#3 directly measured exit temperature of HPJ-processed samples. The attenuator prevents pressure fluctuations in the processed liquids. Color version available online. 


$$
\begin{aligned}
\mathrm{FE} \%= & {[(\text { Initial foam volume including liquid }} \\
& \text { volume }(\mathrm{mL})-10) / 10] \times 100 .
\end{aligned}
$$

Foam stability was measured by allowing the foam to stand at room temperature for $24 \mathrm{~h}$, and the volume of drained liquid and foam was measured at $5 \mathrm{~min}, 15$ min, $1 \mathrm{~h}, 5 \mathrm{~h}$, and $24 \mathrm{~h}$.

\section{Ultracentrifugation and Freeze Drying of Milk Fractions}

The HPJ-processed milks $(20 \mathrm{~mL})$ were ultra-centrifuged using a S50-A rotor (Sorval MTX 150 MicroUltracentrifuge; ThermoScientific Asheville, NC) at 20,000, 50,000, and 100,000 $\times g$ for $30 \mathrm{~min}$. A separate centrifuge (JS-5.3 rotor; Avanti J-E, Beckman Coulter, Austin, TX) was used to centrifuge samples at 6,000 $\times g$. The centrifuged samples were separated into supernatant (top fraction), serum (middle fraction), and precipitate (bottom fraction) and frozen at $-18^{\circ} \mathrm{C}$. A portion of the separated samples was freeze-dried using Virtis Genesis Pilot Lyophilizer (SP Scientific, Warminster, PA). Freeze-dried fractions were further analyzed for fat and protein content.

The sum of all 3 fractions was calculated to ensure that the total solids (\% wt/vol) of freeze-dried fractions corresponded to original total solids $(\sim 12.25 \% \mathrm{wt} / \mathrm{vol})$ in pasteurized whole milk.

\section{Fat Analysis of Freeze-Dried Fractions}

The crude fat content of freeze-dried samples was determined using a fat extractor (Ankom XT15, Ankom Technology, Macedon, NY). Samples were weighed $(0.2-0.3 \mathrm{~g})$ in duplicate for each experimental unit (replicate) into preweighed filter bags and heat-sealed. The crude fat was extracted for $60 \mathrm{~min}$ at $90^{\circ} \mathrm{C}$ using petroleum ether. After extraction, samples were dried for $7 \mathrm{~min}$ at $105^{\circ} \mathrm{C}$, cooled in a desiccant pouch to room temperature, and weighed. Crude fat percentage was calculated using Equation [2]:

$$
\text { Fat }(\%)=\frac{w_{\text {sample }}-w_{\text {after extraction }}}{w_{\text {sample }}} \text {, }
$$

where $w_{\text {sample }}$ is the weight of the freeze-dried sample and $w_{\text {after extraction }}$ is the weight of the sample after the extraction protocol. The sum of fat content of all 3 fractions was calculated to corroborate that the total fat content (\%) of freeze-dried samples corresponded to the total fat content $(\sim 3.41 \%$, wt/vol $)$ in pasteurized whole milk.

\section{Protein Analysis of Freeze-Dried Fractions}

Nitrogen content of freeze-dried fractions was measured by Dumas method using a nitrogen analyzer (Leco FP528, Leco Corp., St. Joseph, MI) and CP content was calculated by multiplying the total $\mathrm{N}$ content by a conversion factor of 6.38 . One $\mathrm{N}$ determination was done for each of 4 replicates corresponding to each pressure treatment and fraction. The sum of the protein content of all 3 fractions was calculated to ensure total protein content $(\%)$ of freeze-dried samples corresponded to total protein $(\sim 3.30 \% \mathrm{wt} / \mathrm{vol})$ in pasteurized whole milk.

\section{Statistical Analysis}

Samples processed at $5^{\circ} \mathrm{C}$ and $55^{\circ} \mathrm{C}$ using $\mathrm{HE} \# 1$ were considered replicates because no significant differences due to temperature were found for any of the measured experimental variables $(P>0.1)$. Experiments were analyzed as completely randomized designs with 4 replicates using SAS software (version 9.4, SAS Institute Inc., Cary, NC). Significance for the linear regression was tested using a linear contrast in an orthogonal polynomial for apparent fat globule size. Foaming properties were analyzed using repeated measures over time. Viscosity and migration of fat and protein was analyzed using least significant difference (LSD) to generate $95 \%$ confidence intervals for any means in which ANOVA showed significant differences. The differences were considered statistically significant for $P \leq 0.05$.

\section{RESULTS AND DISCUSSION}

Pasteurized whole milk was processed by HPJ from 125 to $500 \mathrm{MPa}$ (in $125-\mathrm{MPa}$ increments) with $\mathrm{HE \# 1}$ set at $5^{\circ} \mathrm{C}$ or $55^{\circ} \mathrm{C}$ (Figure 1). We used different temperatures in $\mathrm{HE \# 1}$ in an attempt to control potential temperature-pressure dependent structural changes of fat and proteins in milk. However, there were no significant difference in the observed results due to $\mathrm{HE \#} 1$ set at $5^{\circ} \mathrm{C}$ or $55^{\circ} \mathrm{C}(P>0.1)$. Therefore, data collected at $5^{\circ} \mathrm{C}$ and $55^{\circ} \mathrm{C}$ were considered replicates. The initial temperature of the milk before HPJ processing was $4^{\circ} \mathrm{C}$ in all cases. The recorded temperature remained between 19 and $22^{\circ} \mathrm{C}$ for $\mathrm{TC} \# 1$ and between 26 and $29^{\circ} \mathrm{C}$ for TC\#2 when milk was processed from 125 to $500 \mathrm{MPa}$ (Figure 1). The relatively low milk flow rate used in these experiments likely resulted in the equipment's thermal inertia dictating the final temperature readings. The temperature of the milk collected immediately after HPJ processing (TC\#3) from 125 to $500 \mathrm{MPa}$ increased linearly by approximately $10^{\circ} \mathrm{C}$ for 
every $125 \mathrm{MPa}\left(\mathrm{R}^{2}=0.99\right)$, which was expected due to shear stress-dependent increase in temperature in the high-pressure diamond nozzle. Although the samples were cooled after processing, a confounding effect of temperature and pressure over milk components occurred in samples processed at $>250 \mathrm{MPa}$. Mohan et al. (2016) also reported an increase in temperature with HPJ-processed pasteurized skim milk subjected to pressures of 0 to $500 \mathrm{MPa}$ in $100-\mathrm{MPa}$ increments. However, the temperature increased from $8^{\circ} \mathrm{C}$ to $30^{\circ} \mathrm{C}$ when processed from 400 to $500 \mathrm{MPa}$, because a lower capacity heat exchanger (HE\#2) was used to cool the milk immediately after HPJ processing (Mohan et al., 2016).

The temperature increase for whole milk ranges from approximately 15 to $20^{\circ} \mathrm{C} / 100 \mathrm{MPa}$ when milk is processed using HPH (Hayes and Kelly, 2003; Thiebaud et al., 2003; Hayes et al., 2005; Pereda et al., 2007), due to both adiabatic heating and shear-induced heating in the homogenization valve. The observed range in temperature increase is probably explained by differences in processing equipment (thermal inertia), nozzle diameter causing different shear-induced heating (i.e., smaller nozzles generate more shear-induced heating), and heat exchanger cooling capacity determining final product temperature after processing. In the current study, the flow rate increased from approximately 13 to $24 \mathrm{~mL} / \mathrm{s}$ at HPJ processing pressures from 125 to 500 $\mathrm{MPa}$, respectively. The flow rate was dictated by the specific intensifying pump power and the diameter of the nozzle $(10 \mu \mathrm{m})$.

\section{Effect of HPJ Processing on Physical Properties of Whole Milk}

The apparent particle size distribution of the control and HPJ-processed milk at $125 \mathrm{MPa}$ showed a monomodal distribution, whereas samples processed at 250 , 375 , and $500 \mathrm{MPa}$ showed a bimodal distribution (Figure $2 \mathrm{~A}$ ). We detected no significant differences between the volume-mean diameter $\left(d_{4,3}\right)$ of the control milk and milk processed at $125 \mathrm{MPa}\left(d_{4,3}<1 \mu \mathrm{m}\right)$. However, control milk and milk samples processed at 250, 375, and $500 \mathrm{MPa}$ did differ with $d_{4,3}>10 \mu \mathrm{m}(P<0.05$; Figure 2B). The apparent particle size of HPJ-processed whole milk increased significantly after processing at $375 \mathrm{MPa}\left(d_{4,3}=32 \pm 0.7 \mu \mathrm{m}\right)$, whereas a reduction in apparent particle size was observed after processing at maximum pressure $\left(500 \mathrm{MPa} ; d_{4,3}=22 \pm 0.7 \mu \mathrm{m}\right.$; $P<0.05)$. A similar pattern was observed by Mohan et al. (2016) when processing skim milk using HPJ, where a significant increase in apparent particle size of casein micelles was observed with samples processed at 250 and $375 \mathrm{MPa}$, followed by a significant decrease at $500 \mathrm{MPa}$. Those authors suggested that the high shear-induced temperature in the HPJ nozzle caused hydrophobic reaggregation or compaction of dissociated casein proteins into comparatively larger micelles. This mechanism can also be applied to the present study, as the addition of fat into the system increases hydrophobic interactions, resulting in casein-fat aggregates at processing pressures $\geq 250 \mathrm{MPa}$. An increase in particle size was also reported when whole milk was processed using HPH from 150 to $250 \mathrm{MPa}$ (Hayes and Kelly, 2003; Hayes et al., 2005). Those authors proposed that due to increased particle size reduction in HPH compared with conventional homogenization, a greater amount of surface-active material was required
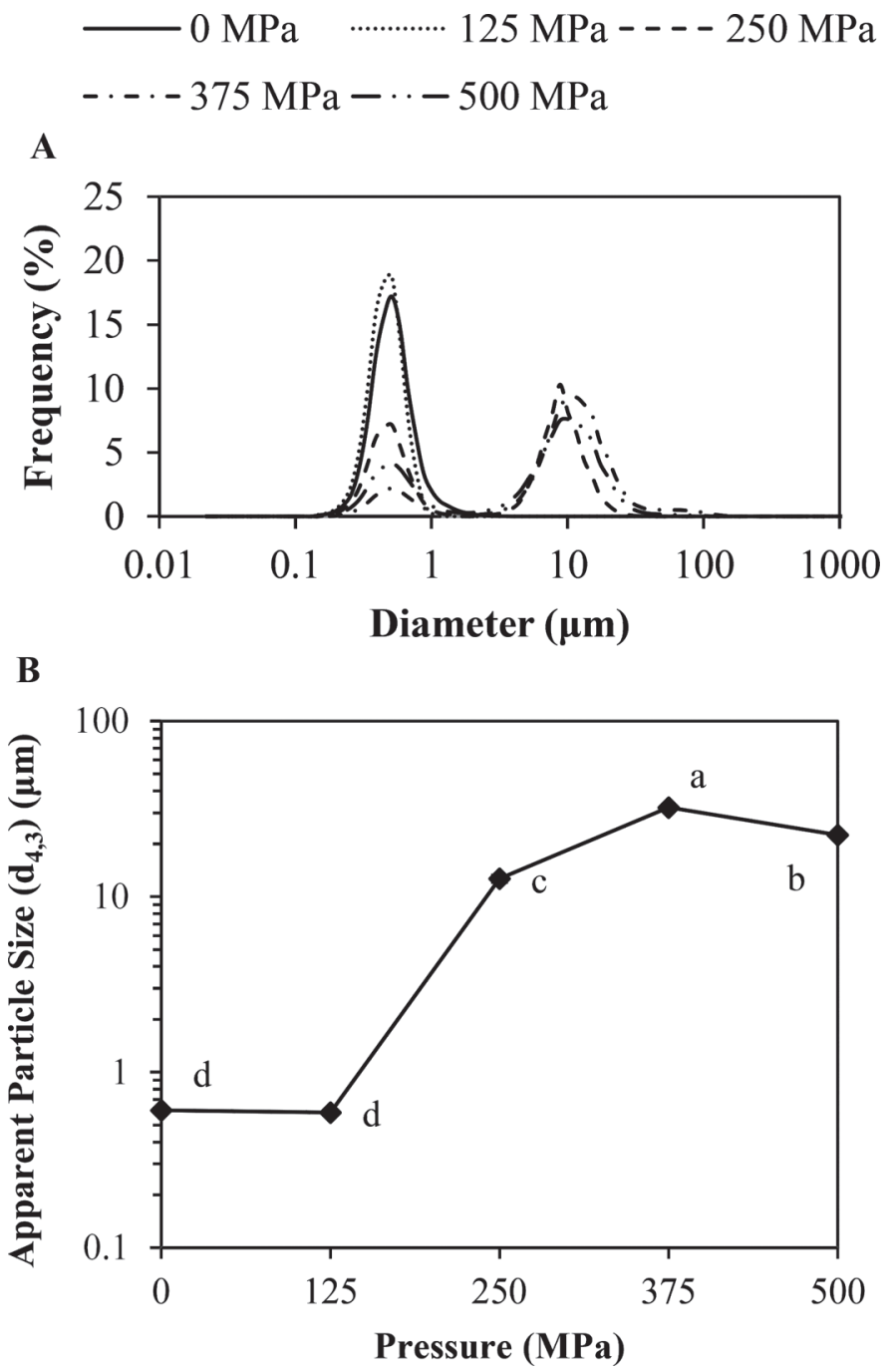

Figure 2. (A) Apparent particle size distribution and (B) volumemean diameter $d_{4,3}$ (in $\mu \mathrm{m}$ ) of pasteurized whole milk (control) and milk processed by high-pressure jet at 125 to $500 \mathrm{MPa}$ gauge pressure. Different letters $(\mathrm{a}-\mathrm{d})$ indicate significant differences using Tukey $(\alpha$ $=0.05)$. 
to cover the newly exposed fat interface, resulting in both casein and fat reaggregation and the formation of comparatively larger fat globules after processing at $250 \mathrm{MPa}$ (Hayes and Kelly, 2003).

After the addition of $0.4 \mathrm{M}$ trisodium citrate $+4 \%$ SDS to disperse any casein proteins adsorbed to the fat aggregates, the apparent fat globule size transitioned into a monomodal distribution for all pressures (Figure 3A) with mean diameters ranging from 0.5 to $0.7 \mu \mathrm{m}$ (Figure 3B). These values are comparable to those reported for conventionally homogenized whole milk (0.5-0.6 $\mu \mathrm{m}$; Walstra et al., 2006). A small reduction in apparent fat globule diameter was observed as processing pressure increased from 125 to $500 \mathrm{MPa}$ $(P<0.01$; Figure 3B). Both temperature and pressure have a major effect in determining the final fat globule size in commercial milk homogenization at $<20$ $\mathrm{MPa}$. At sample temperatures $<40^{\circ} \mathrm{C}$, a portion of milkfat is in crystalline form, reducing the efficiency of the homogenizer in terms of fat globule size reduction (Gunstone and Padley, 1997). Our experiments on the effect of temperature were inconclusive, probably due to the relatively large equipment temperature inertia compared with the low flow rate of the HPJ equipment.

The presence of foam was observed with increasing pressure during sample collection of HPJ-processed whole milk. However, the overall density of the HPJprocessed milk remained constant at approximately $1.02 \mathrm{~g} / \mathrm{mL}(P>0.10)$ regardless of processing pressure. All samples exhibited Newtonian flow behavior. The viscosity of the control and milk treated at 125 $\mathrm{MPa}$ did not differ significantly $(2.0 \pm 0.15 \mathrm{mPa} \cdot \mathrm{s} ; P>$ 0.97). Milk samples subjected to pressures of 250 and $375 \mathrm{MPa}$ showed a linear increase in viscosity, reaching a maximum of approximately $5.0 \mathrm{mPa} \cdot \mathrm{s}(P<0.05$; Figure 4), followed by a relative viscosity drop after milk was processed at $500 \mathrm{MPa}(3.7 \pm 0.15 \mathrm{mPa} \cdot \mathrm{s} ; P$ $<0.01)$. The observed changes in viscosity correlated significantly with results for apparent particle size $\left(\mathrm{R}^{2}\right.$ $=0.96 ; P<0.01)$, as both parameters increased with increasing pressure up to $375 \mathrm{MPa}$ and subsequently decreased at $500 \mathrm{MPa}$.

The upturn in viscosity as HPJ processing pressure increased $\geq 250 \mathrm{MPa}$ was also observed in HPJprocessed pasteurized skim milk processed from 200 to $500 \mathrm{MPa}$ (Mohan et al., 2016), indicating that the structural modifications to casein micelles contributed to observed viscosity changes in whole milk.

An increase in viscosity has also been observed in $\mathrm{HPH}$ of raw whole milk processed at pressures $>200$ MPa (Pereda et al., 2007; Amador-Espejo et al., 2014). The formation of larger fat aggregates due to insufficient casein and whey proteins to cover the large sur-

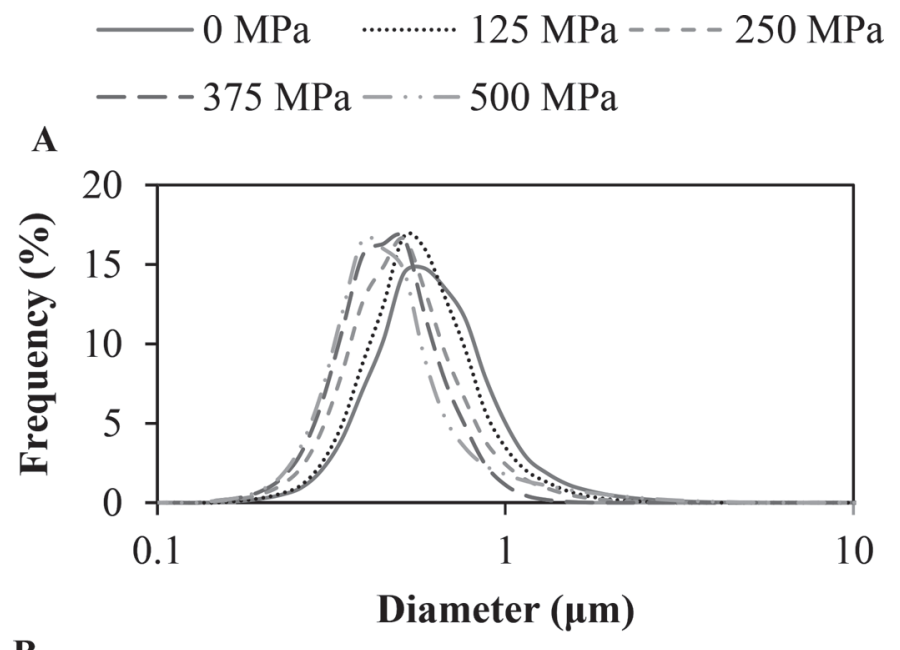

B

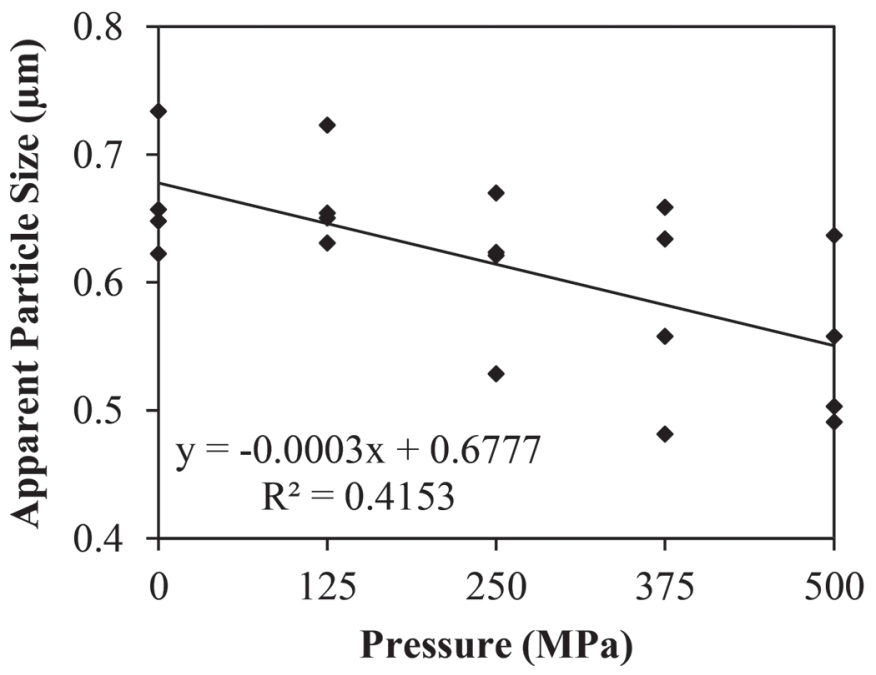

Figure 3. (A) Apparent fat globule size distribution and (B) volume-mean diameter $d_{4,3}$ (in $\mu \mathrm{m}$ ) of pasteurized whole milk (control) and milk processed by high-pressure jet at 125 to $500 \mathrm{MPa}$ with dissociating medium (0.04\% trisodium citrate $+4 \%$ SDS). Significance for the linear regression was tested using a linear contrast in an orthogonal polynomial for 4 replications $(P<0.05)$.

face area of newly formed fat globules after HPH was thought to be the mechanism behind increased viscosity at processing pressures $>300 \mathrm{MPa}$ and initial temperature of $85^{\circ} \mathrm{C}$ (Pereda et al., 2007; Amador-Espejo et al., 2014). The thermal denaturation of whey proteins (especially $\beta-\mathrm{LG}$ ) and subsequent polymerization is also thought to contribute to increased viscosity (AmadorEspejo et al., 2014). In contrast, SDS-PAGE analysis of HPJ-processed skim milk showed little whey protein denaturation when samples were rapidly cooled after processing (Mohan et al., 2016). Because of similar exit temperatures of HPJ-processed whole milk, the casein structural modifications and the interactions between fat and caseins (i.e., casein-fat aggregates) were prob- 


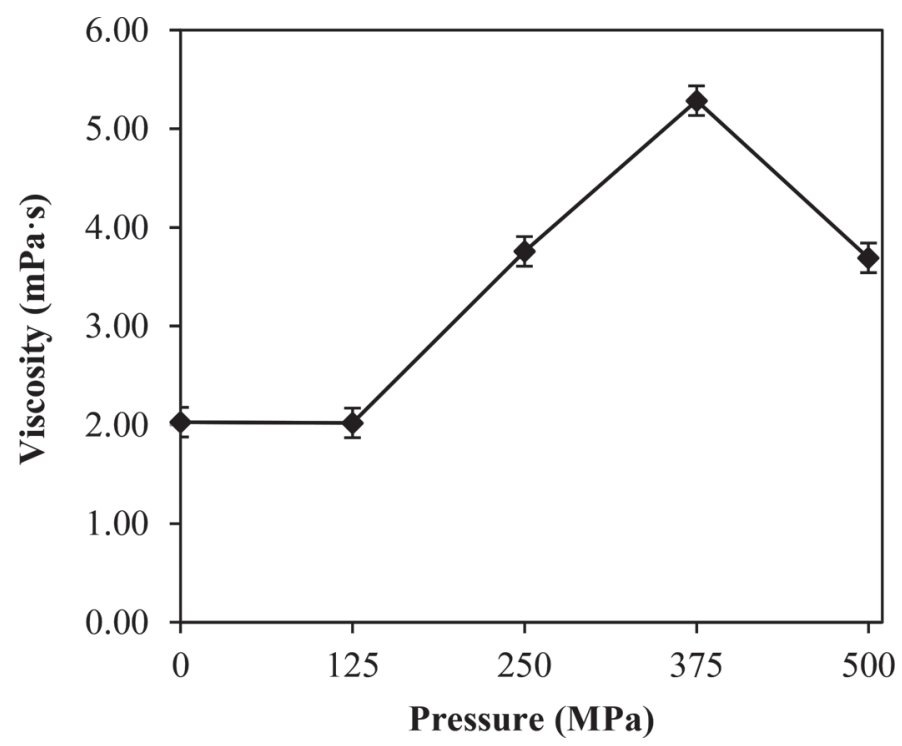

Figure 4. Newtonian viscosity of pasteurized whole milk (0 MPa gauge pressure) and milk processed by high-pressure jet at pressures from 125 to $500 \mathrm{MPa}$. Bars represent 95\% CI for the mean.

ably the dominant cause of changes in viscosity in the current experiment.

The formation of milk foam depends on the ability of amphiphilic milk proteins to rapidly migrate and rearrange in the air-water interface, reducing the interfacial tension between the air and water, thus facilitating the formation of small gas bubbles (Anderson et al., 1988; Huppertz, 2010). In the present study, foamability was quantified as the foam expansion index $(\mathrm{FE} \%)$ of $10 \mathrm{~mL}$ of milk at $4^{\circ} \mathrm{C}$. Figure 5 shows the foamability of the control and HPJ-processed milks at time 0. The control samples exhibited relatively high foamability $(\mathrm{FE} \%=$ $80 \pm 3 \% \mathrm{vol} / \mathrm{vol}$ ), consistent with the known native foaming properties of milk at neutral pH (Dickinson, 2003; Kamath et al., 2008). All samples processed using HPJ showed improved foamability, reaching a maximum $\mathrm{FE} \%$ of $148 \pm 3 \%$ (vol/vol) after processing the milk at $500 \mathrm{MPa}$ (>85\% increase in foamability). No significant correlation was found between initial foam expansion and apparent particle size or viscosity $(P>$ 0.13 ) because the decrease in particle size and viscosity when processing whole milk at $500 \mathrm{MPa}$ did not affect the initial foam expansion of milk. Similar foamability results were observed by Harte et al. (2016), where an increase in initial $\mathrm{FE} \%$ was observed after processing skim milk using HPJ. The previous study suggested that the dissociation of casein micelles into surfaceactive casein proteins improved foamability compared with that of untreated milk and milk processed at 100 MPa.
The stability of the foams was measured by holding samples for $5 \mathrm{~min}, 15 \mathrm{~min}, 1 \mathrm{~h}, 5 \mathrm{~h}$, and $24 \mathrm{~h}$ after foaming at room temperature (Figure 6 ). In less than $1 \mathrm{~h}$, the foams created from the control and milk processed at $125 \mathrm{MPa}$ collapsed, whereas those created from samples processed at 375 and $500 \mathrm{MPa}$ retained the same $\mathrm{FE} \%$ as as time 0 . All foams made from whole milk processed using HPJ $\leq 250 \mathrm{MPa}$ collapsed completely after $5 \mathrm{~h}$ $(\mathrm{FE} \%=0)$, whereas those created from samples processed at 375 and $500 \mathrm{MPa}$ showed FE\% from $20 \pm 3 \%$ (vol/vol) to $40 \pm 3 \%$, respectively. After $24 \mathrm{~h}$, all foams completely collapsed. In a contrasting previous study, foams made from skim milk processed using HPJ from 200 to $500 \mathrm{MPa}$ retained approximately $55 \%$ of their stability after $24 \mathrm{~h}$ (Harte et al., 2016). Our results were consistent with previous reports in which considerable differences were observed between the foam stability of pasteurized skim and whole milk (Kamath et al., 2008). Whole milk foamed at temperatures between 5 and $35^{\circ} \mathrm{C}$ was highly unstable due to solid fats puncturing the foam lamella and liquid fat spreading onto the air-serum interface and destabilizing the foam bubbles (Kamath et al., 2008). It is also known that there is competition between milk proteins, fatty acids, and phospholipids at the air-serum interface that may cause foam instability; however, the extent of competition between different surface-active agents was not measured in this study.

\section{Effect of HPJ Processing on Fat and Protein Migration}

Samples $(20 \mathrm{~mL})$ of HPJ-processed milk were centrifuged at $6,000,20,000,50,000$, and $100,000 \times g$ for 30 min to determine the relative stability and aggregation patterns of the protein and fat components in whole

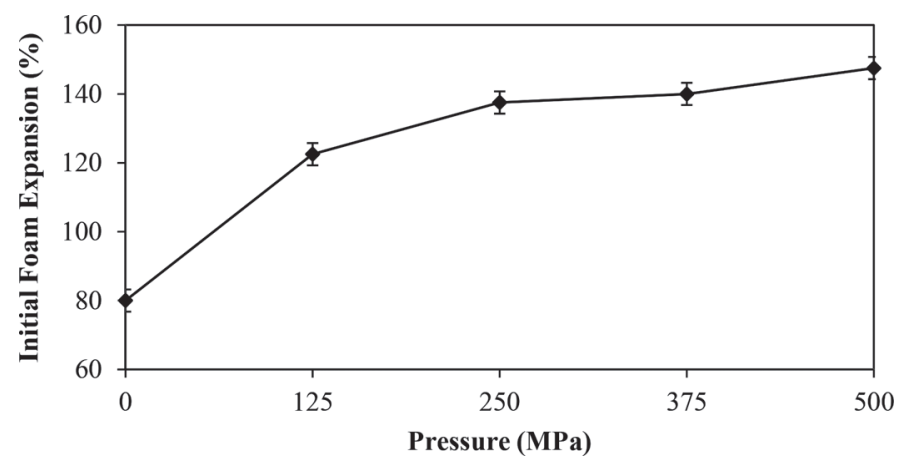

Figure 5. Initial foam expansion $(\%$; time $=0)$ for whole milk at $4^{\circ} \mathrm{C}$ after processing using high-pressure jet from 0 to $500 \mathrm{MPa}$ gauge pressure. Bars represent $95 \%$ CI for the mean. 
milk. In all cases, 3 distinctive layers (supernatant, serum, and precipitate) were observed. The fractions were separated, freeze-dried, and weighed. The weight of the 3 dry fractions combined ranged from 2.51 to $2.71 \mathrm{~g}$, matching the weight of total solids in liquid whole milk ( $\sim 12.7 \%$ wt/vol solids; Figures $7 \mathrm{~A}, 8 \mathrm{~A}, 9 \mathrm{~A})$.

Regardless of centrifugal acceleration, the dry weight values for all fractions remained relatively constant for the control milk and milk processed at $125 \mathrm{MPa}$. However, at processing pressures from 125 to $375 \mathrm{MPa}$, we observed significant changes in total dry weight of the 3 fractions. Whole milk samples that were processed between 125 and $375 \mathrm{MPa}$ and then separated using low acceleration centrifugation (i.e., 6,000 $\times g$ ) exhibited a reduction in the dry weight of the supernatant fraction (Figure 7A; $P<0.05$ ) and a corresponding increase in the precipitate fraction (Figure $8 \mathrm{~A}$ ), indicating that large casein-casein and casein-fat aggregates were formed as a result of HPJ processing. Between 375 and $500 \mathrm{MPa}$, the reduction in dry weight in supernatant and increase of dry weight in the precipitate was not significant.

Studies investigating natural creaming in $\mathrm{HPH}$ whole milk stored at 4 to $5^{\circ} \mathrm{C}$ reported no visible creaming after $7 \mathrm{~d}$ in samples processed from 200 to $300 \mathrm{MPa}$. Reduction in milk fat globule size and increased interactions between fat and proteins (i.e., fat-protein aggregates) as a result of HPH were suggested to be the cause of decrease in creaming compared with untreated milk (Hayes et al., 2005; Pereda et al., 2007). On the other hand, whole milk processed using HPP and stored at $5^{\circ} \mathrm{C}$ showed increased creaming over time at processing pressures $<200 \mathrm{MPa}$, whereas at processing pressures 400 or $600 \mathrm{MPa}$, creaming decreased by $40 \%$ compared with untreated milk (Huppertz et al., 2003). However after $7 \mathrm{~d}$ of storage at $5^{\circ} \mathrm{C}$, the fat content of

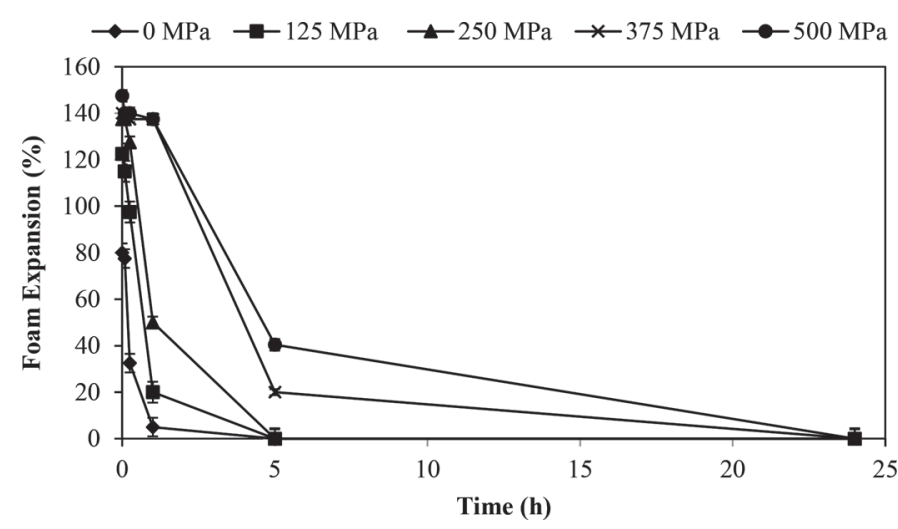

Figure 6. Foam stability of pasteurized whole milk (control) and milk processed by high-pressure jet at 125 to $500 \mathrm{MPa}$ over time (5 min, $15 \mathrm{~min}, 1 \mathrm{~h}, 5 \mathrm{~h}, 24 \mathrm{~h}$ ) at room temperature. Bars represent $95 \%$ CI the mean. the supernatant fraction was not significantly different between different processing pressures. Overall, processing whole milk at pressures $>200 \mathrm{MPa}$ in $\mathrm{HPH}$ and HPJ and pressures $>400 \mathrm{MPa}$ in HPP are required to increase interactions between fat and proteins affecting the creaming rate.

At processing pressures $\geq 200 \mathrm{MPa}$ in $\mathrm{HPH}$, dissociation of casein micelles into individual casein proteins have been observed (Sandra and Dalgleish, 2005; Roach and Harte, 2008) so it was expected that the weight of the supernatant fraction would increase with increasing pressure due to casein protein incorporation. However, the opposite was observed: as the HPJ processing pressure increased $>250 \mathrm{MPa}$, components in the supernatant fraction migrated to the precipitate fraction, as evidenced by a strong negative correlation $(\mathrm{r}=-0.99 ; P<0.01)$ between the 2 fractions (Figures $7 \mathrm{~A}, 8 \mathrm{~A}$ ). The reduction of the supernatant fraction due to fat disruption by homogenization has been widely reported and is the basis for the commercial homogenization of milk using 2-stage valve homogenizers at $\sim 15$ MPa. However, our results indicate that the interaction between fat triglycerides and casein proteins at $\geq 250$ $\mathrm{MPa}$ resulted in stable casein-fat aggregates that did not dissociate, even after centrifugation at $100,000 \times$ $g$ for $30 \mathrm{~min}$. Based on the dry weight results of the supernatant and precipitate fractions after centrifugation, HPJ-processed whole milk would have long-term stability because the casein and casein-fat aggregates formed are considered kinetically stable. A smaller yet significant decrease in the dry weight was also observed for the serum fraction when whole milk was processed using HPJ at $\geq 250 \mathrm{MPa}$ compared with the control ( $P$ $<0.05$; Figure 9A).

To study the stability and formation of fat-fat and casein-fat aggregates, a Soxhlet-based method of fat analysis was performed on the 3 freeze-dried fractions. The weight of the fat content of the freeze-dried fractions combined was between 0.54 and $0.70 \mathrm{~g}$, matching the weight of total fat in milk after freeze-drying $(\sim 3.41 \% \mathrm{wt} / \mathrm{vol}$ fat; Figures 7B, 8B, 9B). Similar to results obtained for the dry weight milk fractions, the fat content of all fractions after centrifugation at $>20,000$ $\times g$ remained constant for the control milk (0 MPa) and the milk processed using HPJ at $125 \mathrm{MPa}$. At processing pressures from 125 to $375 \mathrm{MPa}$, a continuous reduction in fat content in the supernatant fraction $(P$ $<0.05$; Figure 7B) and a continuous increase in the fat content in the precipitate fraction was observed $(P<$ 0.05; Figure 8B), further confirming the results from dry weight fractions that fat migrates with the caseinrich precipitate fraction as a result of HPJ processing. The fat migration patterns were not significantly different when processing pressure increased from 375 to 500 
MPa. The fat content in the serum fraction remained constant regardless of HPJ processing pressure $(P>$ 0.17 ; Figure $8 \mathrm{~B}$ ). The patterns of fat migration to the whey fraction were affected by the various centrifugation accelerations, but the differences in absolute values (grams of fat) were not relevant. The significance of interactions between HPJ processing pressure and ultracentrifugation acceleration were not studied as they were only present in cases were the effect of the main factor (i.e., HPJ) was negligible.

Nitrogen analysis was conducted on the 3 freeze-dried fractions. The protein content of the freeze-dried fractions combined was between 0.51 and $0.68 \mathrm{~g}$, matching the weight of total protein in milk after freeze-drying $(\sim 3.3 \% \mathrm{wt} /$ vol protein; Figures 7C, 8C, 9C). Similar to both dry weight and fat content results, the protein
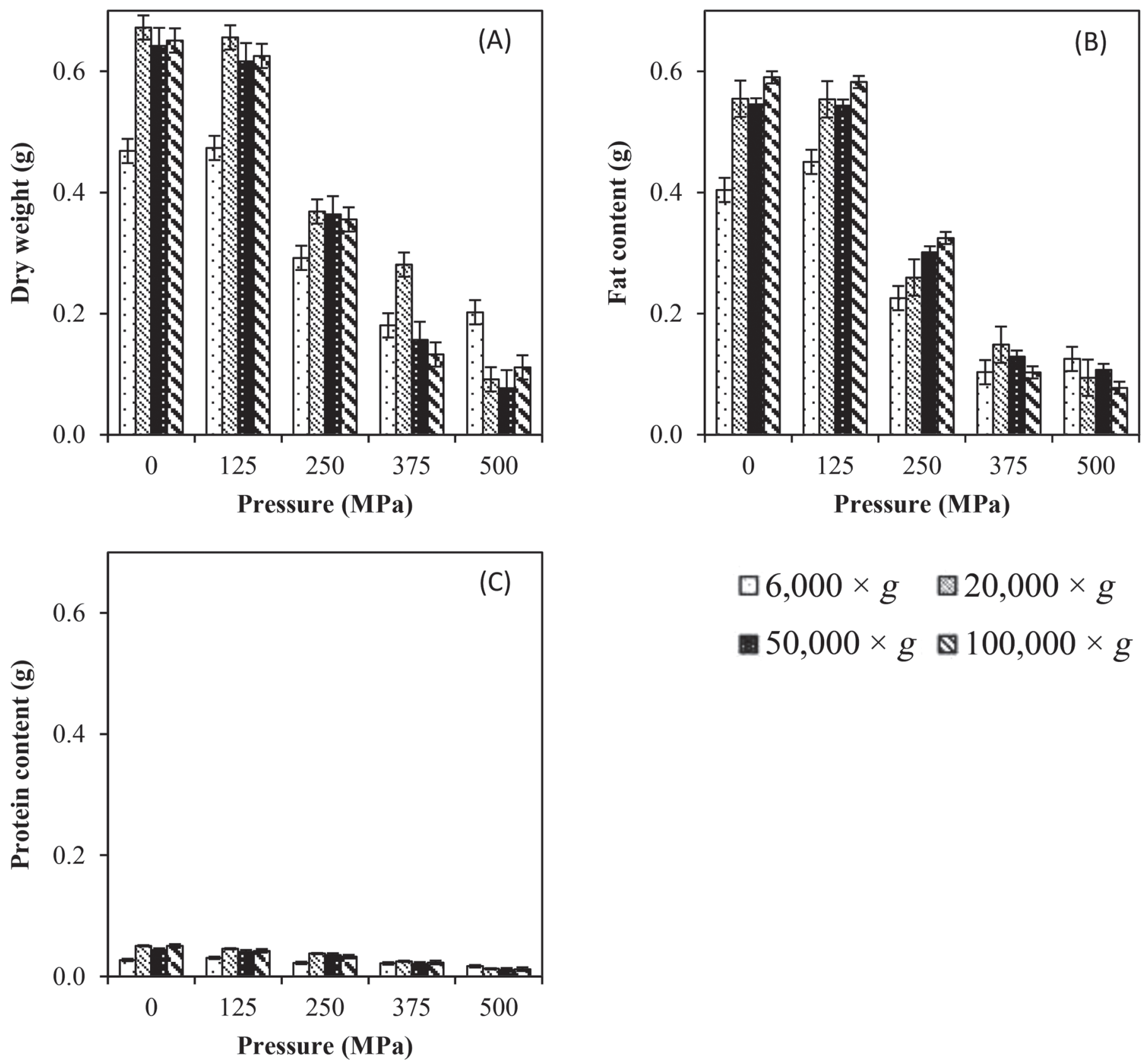

Figure 7. (A) Dry weight, (B) fat content, and (C) protein content of the supernatant fractions of whole milk processed by high-pressure jet at 0 to $500 \mathrm{MPa}$ and centrifuged at 6,000, 20,000, 50,000, and 100,000 $\times \mathrm{g}$. Bars represent 95\% CI for the mean. 
content of all 3 fractions remained relatively constant for the control milks (0 MPa) and milk processed using HPJ at $125 \mathrm{MPa}$. For samples processed at pressures $\geq 250 \mathrm{MPa}$, regardless of centrifugal acceleration, a significant decrease in protein content was observed for supernatant and serum fractions (Figures $7 \mathrm{C}, 9 \mathrm{C} ; P$ $<0.05$ ), and an overall increase in protein content for the precipitate fraction was observed with increasing pressure (Figure $8 \mathrm{C}$ ). The reduction in protein from supernatant and serum fractions and increase in precipitate fractions suggest that both whey proteins and casein proteins in the serum fraction migrated to the precipitate fraction, indicating increased interactions between individual caseins and possibly whey proteins with increasing pressure. Whey protein denaturation at higher temperatures $\left(75-85^{\circ} \mathrm{C}\right)$ can also increase interactions between whey proteins and casein proteins (Walstra et al., 2006), increasing overall protein con-
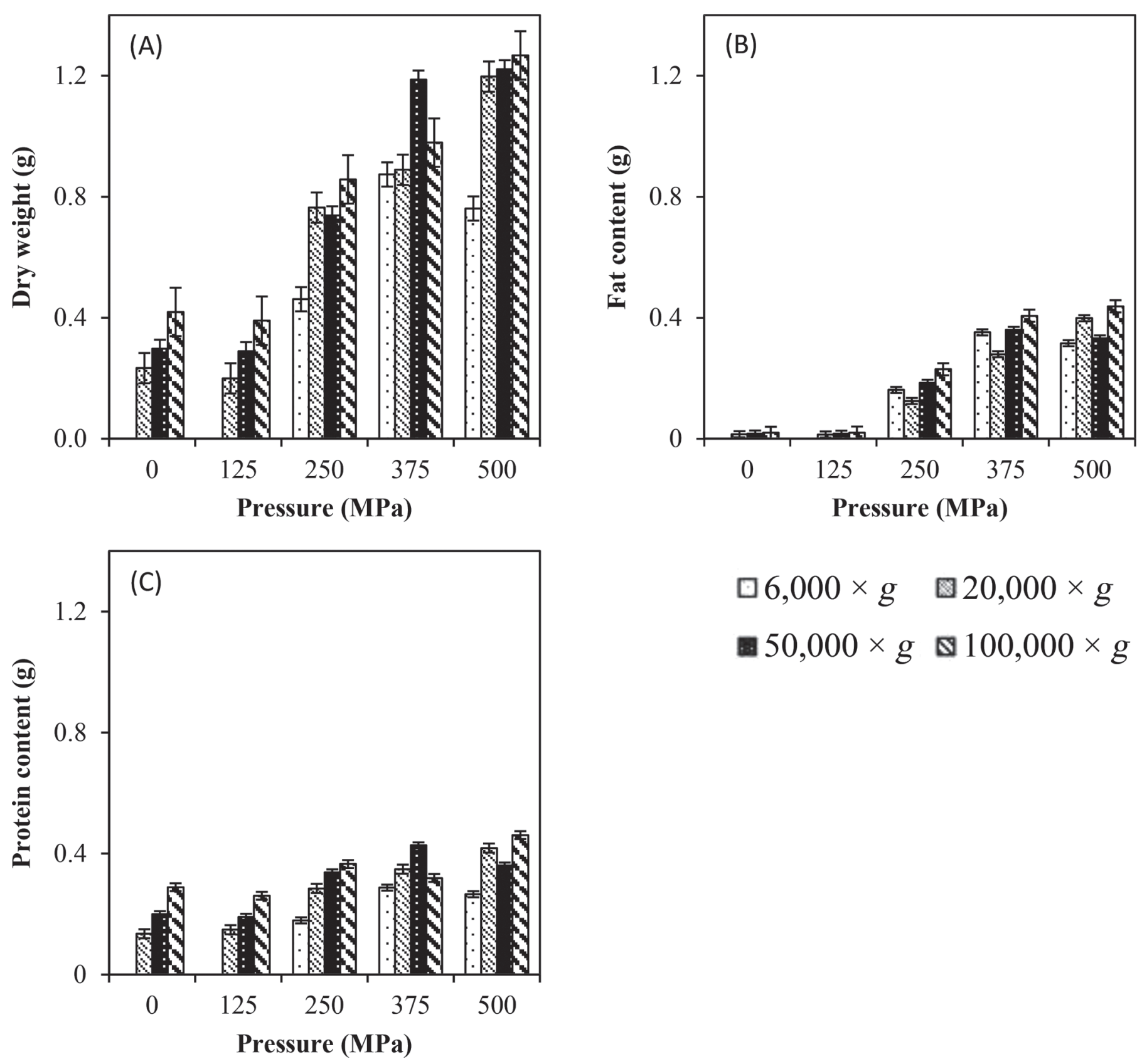

Figure 8. (A) Dry weight, (B) fat content, and (C) protein content of the precipitate fractions of whole milk processed by high-pressure jet at 0 to $500 \mathrm{MPa}$ and centrifuged at 6,000, 20,000, 50,000, and 100,000 $\times \mathrm{g}$. Bars represent $95 \%$ CI for the mean. 
tent in the precipitate fraction. However, because of the low initial temperature of milk and rapid cooling of milk, we assumed that little whey protein denaturation occurred in HPJ-processed whole milk. Preliminary SDS-PAGE under reducing conditions did not show appreciable differences in the bands corresponding to whey versus casein proteins and were consistent with protein content measured using the Dumas method (gels not shown).
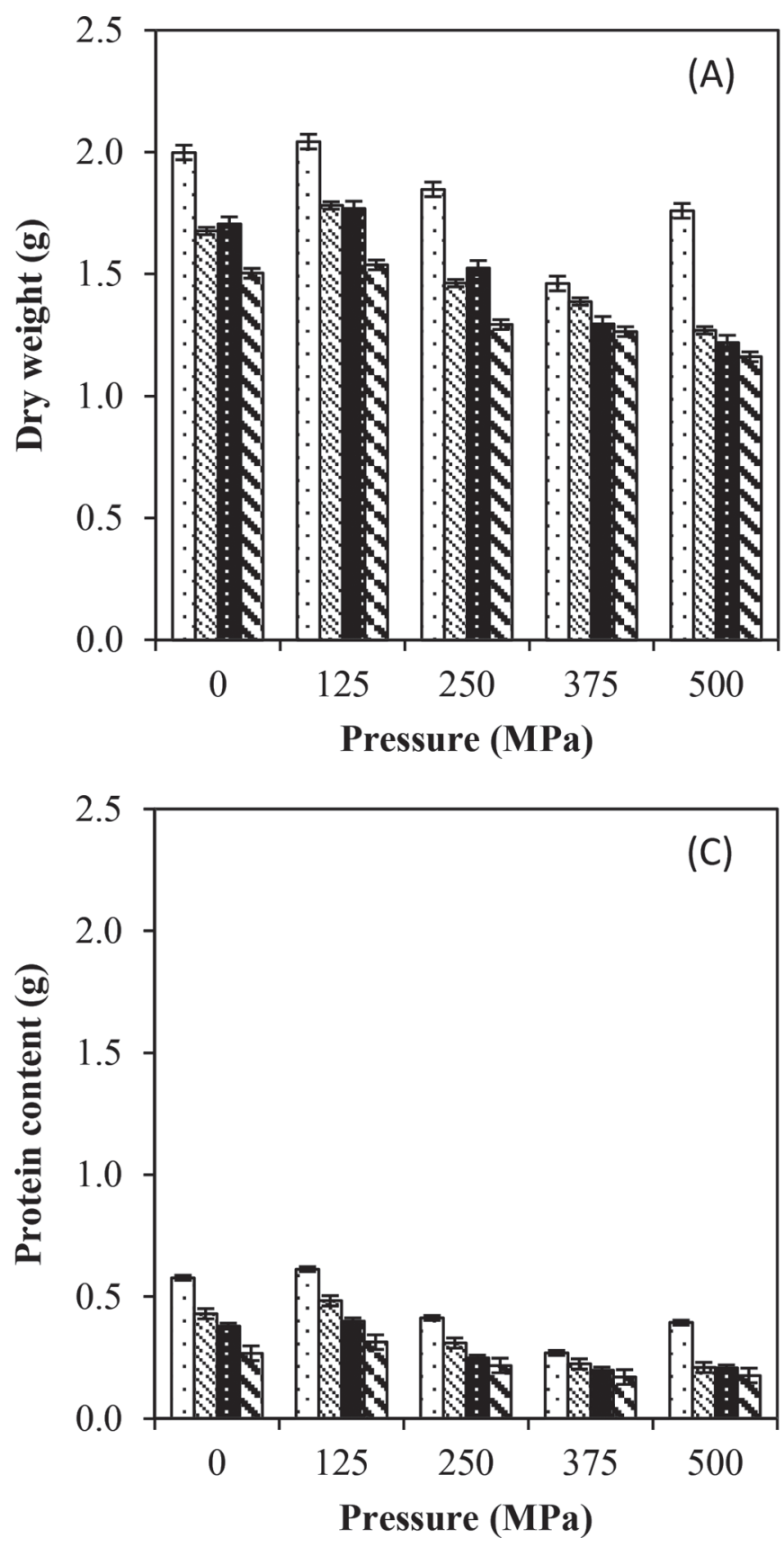

The dissociation of the native casein micelles and the reformation of casein protein aggregates as a result of HPJ, HPP, and HPH of skim milk have been reported previously (Needs et al., 2000; Roach and Harte, 2008; Mohan et al., 2016) and may contribute to increased protein content in the precipitate fraction. A previous study involving pasteurized skim and HPJ processing from 100 to $500 \mathrm{MPa}$ reported increases in casein micelle size with increasing pressure, with a significant

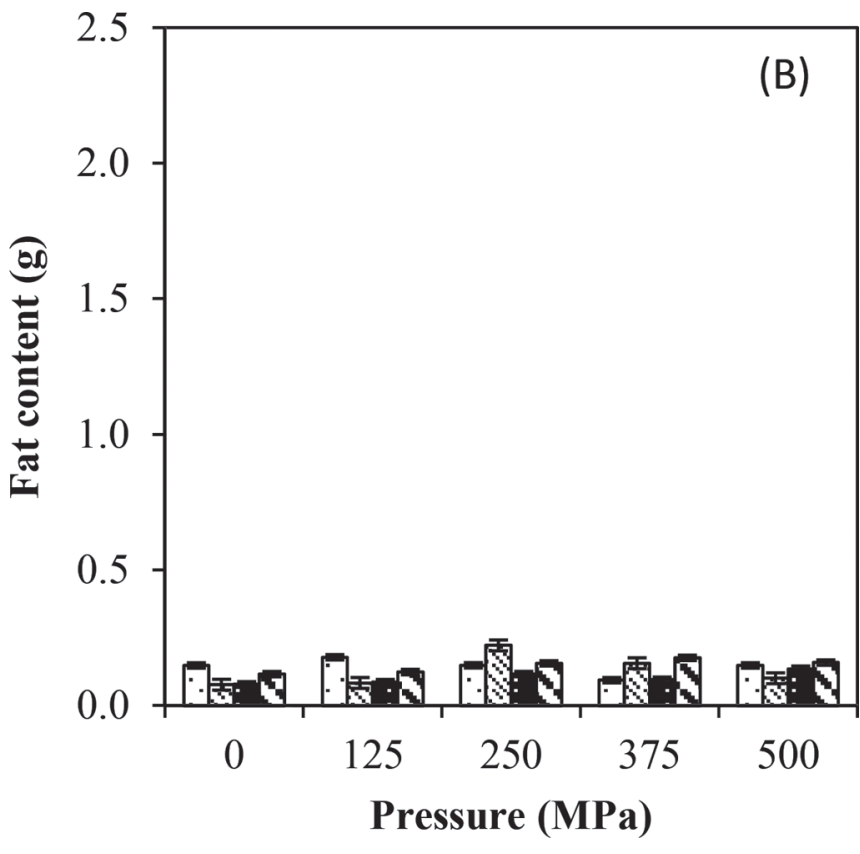

$$
\begin{aligned}
& 6,000 \times g \quad \square 20,000 \times g \\
& 50,000 \times g \otimes 100,000 \times g
\end{aligned}
$$

Figure 9. (A) Dry weight, (B) fat content, and (C) protein content of the serum fractions of whole milk processed by high-pressure jet at 0 to $500 \mathrm{MPa}$ and centrifuged at 6,000, 20,000,50,000, and 100,000 $\times \mathrm{g}$. Bars represent $95 \%$ CI for the mean. 
decrease at $500 \mathrm{MPa}$ (Mohan et al., 2016). The authors suggested that casein aggregation occurred at pressures $>200 \mathrm{MPa}$ as a result of increased hydrophobic interactions caused by an increase in temperature due to shear-induced phenomena after HPJ processing. Roach and Harte (2008) reported an increase in casein micelle size in skim milk processed by HPH at pressures $>200$ $\mathrm{MPa}$, suggesting that increased hydrophobic interactions between submicelles increased micelle size, as the presence of soluble casein proteins was reported to decrease significantly. The collapse or removal of $\kappa$-casein on the surface of the casein micelle due HPP has also been reported (Needs et al., 2000). The solubilization of $\kappa$-casein promotes casein micelle aggregation as negative charges and electrostatic repulsions are reduced, resulting in increased casein micelle size. The changes to casein micelle structure and its relation to casein micelle size at processing pressures $>200 \mathrm{MPa}$ may also contribute to the increase in protein content in the precipitate fraction.

Overall, major changes in migration patterns of fat and protein in whole milk were demonstrated in HPJ-processed samples at pressures $\geq 250 \mathrm{MPa}$ with centrifugal accelerations $>20,000 \times g$. The absence of creaming and the observed co-precipitation of fat and protein after centrifugal accelerations up to 100,000 $\times g$ for $1 \mathrm{~h}$ demonstrated the strength of interactions between milkfat triglycerides and casein protein.

\section{CONCLUSIONS}

The use of HPJ as a nonthermal technology to create novel dairy-based ingredients with specific functionality was demonstrated by increased viscosity and foaming properties observed in whole milk processed at $\geq 250$ MPa. The modification of the casein micelle and the formation of casein-fat complexes were evidenced by the significant differences in the migration patterns of fat and protein after ultracentrifugation of milk processed using HPJ $\geq 250 \mathrm{MPa}$ compared with the control. We detected an overall decrease in fat content of the supernatant fraction after ultracentrifugation, with a corresponding increase in the precipitate fraction, with increasing HPJ processing pressure.

\section{ACKNOWLEDGMENTS}

This research was supported by the Department of Food Science, College of Agriculture, Pennsylvania State University (University Park). We acknowledge partial support from the USDA (Washington, DC) through the Hatch project "Improving the Physical and Nutritional Functionality of Food Ingredients" (Accession No. 1002916).

\section{REFERENCES}

Amador-Espejo, G. G., A. Suàrez-Berencia, B. Juan, M. E. Bárcenas, and A. J. Trujillo. 2014. Effect of moderate inlet temperatures in ultra-high-pressure homogenization treatments on physicochemical and sensory characteristics of milk. J. Dairy Sci. 97:659-671. https://doi.org/10.3168/jds.2013-7245.

Anderson, M., R. Ettelaie, E. Dickinson, and G. Stainsby. 1988. Dairy Foams. E. Dickinson and G. Stainsby, ed. Elsevier Applied Science, London, UK.

De Feijter, J. A., J. Benjamins, and M. Tamboer. 1987. Adsorption displacement of proteins by surfactants in oil-in-water emulsions. Colloids Surf. 27:243-266. https://doi.org/10.1016/0166 $-6622(87) 80145-2$.

Dickinson, E. 2003. Interfacial, Emulsifying, and Foaming Properties of Milk Proteins. Springer, New York, NY.

Feijoo, S. C., W. W. Hayes, C. E. Watson, and J. H. Martin. 1997. Effects of Microfluidizer technology on Bacillus licheniformis spores in ice cream mix. J. Dairy Sci. 80:2184-2187. https://doi.org/10 .3168/jds.S0022-0302(97)76166-6.

Giardina, C., V. Pelizzola, A. Avalli, S. Iametti, and T. M. P. Cattaneo. 2004. Functional properties of milk protein hydrolysates obtained by controlled enzymatic hydrolysis. Milchwissenschaft 59:476-479.

Gunstone, F. D., and F. B. Padley. 1997. Lipid Technologies and Applications. Marcel Dekker, New York, NY.

Harte, F. M., M. C. Martinez, and M. S. Mohan. 2016. Foaming and emulsifying properties of high pressure jet processing pasteurized milk. Penn State Res. Found. US Pat. No. 0,374,359.

Hayes, M. G., P. F. Fox, and A. L. Kelly. 2005. Potential applications of high pressure homogenisation in processing of liquid milk. J. Dairy Res. 72:25-33. https://doi.org/10.1017/S0022029904000524.

Hayes, M. G., and A. L. Kelly. 2003. High pressure homogenisation of raw whole bovine milk (a) effects on fat globule size and other properties. J. Dairy Res. 70:297-305. https://doi.org/10.1017/ S0022029903006320.

Huppertz, T. 2010. Foaming properties of milk: A review of the influence of composition and processing. Int. J. Dairy Technol. 63:477488. https://doi.org/10.1111/j.1471-0307.2010.00629.x.

Huppertz, T., P. F. Fox, and A. L. Kelly. 2003. High pressure-induced changes in the creaming properties of bovine milk. Innov. Food Sci. Emerg. Technol. 4:395-402. https://doi.org/10.1016/S1466 -8564(03)00057-2.

Huppertz, T., M. A. Smiddy, H. D. Goff, and A. L. Kelly. 2011. Effects of high pressure treatment of mix on ice cream manufacture. Int. Dairy J. 21:718-726. https://doi.org/10.1016/j.idairyj.2010.12 .005 .

Jafari, S. M., Y. He, and B. Bhandari. 2007. Production of sub-micron emulsions by ultrasound and microfluidization techniques. J. Food Eng. 82:478-488. https://doi.org/10.1016/j.jfoodeng.2007.03.007.

Kamath, S., T. Huppertz, A. V. Houlihan, and H. C. Deeth. 2008. The influence of temperature on the foaming of milk. Int. Dairy J. 18:994-1002. https://doi.org/10.1016/j.idairyj.2008.05.001.

Lodaite, K., F. Chevalier, E. Armaforte, and A. L. Kelly. 2009. Effect of high-pressure homogenisation on rheological properties of rennet-induced skim milk and standardised milk gels. J. Dairy Res. 76:294-300. https://doi.org/10.1017/S0022029909004117.

Mohan, M. S., R. Ye, and F. Harte. 2016. Initial study on high pressure jet processing using a modified waterjet on physicochemical and rennet coagulation properties of pasteurized skim milk. Int. Dairy J. 55:52-58. https://doi.org/10.1016/j.idairyj.2015.12.004.

Mussa, D. M., and H. S. Ramaswamy. 1997. Ultra-high pressure pasteurization of milk: Kinetics of microbial destruction and changes in physio-chemical characteristics. Lebensm. Wiss. Technol. 30:551-557. https://doi.org/10.1006/fstl.1996.0223.

Needs, E. C., R. A. Stenning, A. L. Gill, V. Ferragut, and G. T. Rich. 2000. High-pressure treatment of milk: Effects on casein micelle structure and on enzymatic coagulation. J. Dairy Res. 67:31-42.

Palou, E., A. López-Malo, G. V. Barbosa-Cánovas, J. Welti-Chanes, and B. G. Swanson. 1999. Polyphenoloxidase activity and color of blanched and high hydrostatic pressure treated banana puree. 
J. Food Sci. 64:42-45. https://doi.org/10.1111/j.1365-2621.1999 tb09857.x.

Paquin, P. 1999. Technological properties of high pressure homogenizers: The effect of fat globules, milk proteins, and polysaccharides. Int. Dairy J. 9:329-335. https://doi.org/10.1016/S0958 $-6946(99) 00083-7$.

Pereda, J., V. Ferragut, J. M. Quevedo, B. Guamis, and A. J. Trujillo. 2007. Effects of ultra-high pressure homogenization on microbial and physicochemical shelf life of milk. J. Dairy Sci. 90:1081-1093. https://doi.org/10.3168/jds.S0022-0302(07)71595-3.

Roach, A., and F. Harte. 2008. Disruption and sedimentation of casein micelles and casein micelle isolates under high-pressure homogenization. Innov. Food Sci. Emerg. Technol. 9:1-8. https://doi.org/10 $.1016 /$ j.ifset.2007.03.027.

Sandra, S., and D. G. Dalgleish. 2005. Effects of ultra-high-pressure homogenization and heating on structural properties of casein micelles in reconstituted skim milk powder. Int. Dairy J. 15:10951104. https://doi.org/10.1016/j.idairyj.2004.11.015.

Thiebaud, M., E. Dumay, L. Picart, J. P. Guiraud, and J. C. Cheftel. 2003. High-pressure homogenisation of raw bovine milk: Effects on fat globule size distribution and microbial inactivation. Int. Dairy J. 13:427-439. https://doi.org/10.1016/S0958-6946(03)00051-7.

Tobin, J., S. P. Heffernan, D. M. Mulvihill, T. Huppertz, and A. L. Kelly. 2015. Applications of high-pressure homogenization and microfluidization for milk and dairy products. Pages 93-114 in Emerging Dairy Processing Technologies: Opportunities for the Dairy Industry. Wiley-Blackwell, Ames, IA.

Voigt, D. D., A. L. Kelly, and T. Huppertz. 2015. High-pressure processing of milk and dairy products. Pages 71-92 in Emerging Dairy Processing Technologies: Opportunities for the Dairy Industry. Wiley-Blackwell, Ames, IA.

Walstra, P. 1990. On the stability of casein micelles. J. Dairy Sci. 73:1965-1979. https://doi.org/10.3168/jds.S0022-0302(90)78875 $-3$.

Walstra, P., J. T. M. Wouters, and T. J. Geurts. 2006. Dairy Science and Technology. 2nd ed. CRC/Taylor \& Francis, Boca Raton, FL.

Zobrist, M. R., T. Huppertz, T. Uniacke, P. F. Fox, and A. L. Kelly. 2005. High-pressure-induced changes in the rennet coagulation properties of bovine milk. Int. Dairy J. 15:655-662. https://doi .org/10.1016/j.idairyj.2004.07.025. 